\title{
INTERNET USER'S BEHAVIOR FROM THE STANDPOINT OF THE NEURAL NETWORK THEORY OF SOCIETY: PREREQUISITES FOR THE META-EDUCATION CONCEPT FORMATION
}

\author{
Akhat S Bakirov ${ }^{1}$, Yelizaveta S Vitulyova ${ }^{1}$, Andrey A Zotkin², Ibragim E Suleimenov ${ }^{2, *}$ \\ ${ }^{1}$ Almaty University of Power Engineering and Telecommunications, Almaty, Republic of Kazakhstan (axatmr@mail.ru, \\ lizavita@list.ru) \\ ${ }^{2}$ Crimean Federal University, Simferopol, Russian Federation (and.zotkin@yandex.ru, esenych@yandex.kz*)
}

KEY WORDS: Noosphere, Meta-education, Neural networks, The essence of intelligence, Media persons, Infocommunication space.

\begin{abstract}
:
An analysis of the behavior of Internet users from the point of view of their preferences in the choice of information sources and the effectiveness of their impact is presented. It is shown that the modern infocommunication space has undergone qualitative changes in the most recent time, and these transformations are already having a pronounced impact on higher education, mainly through the factor of competition between information sources. It is shown that these transformations can be interpreted as the evolution of the noosphere, which is considered as a global infocommunication network, in which non-trivial transpersonal information objects are formed. Their existence leads to the fact that the human intellect has a dual nature - both individual and collective principles are present in it at the same time. The latter is responsible for such phenomena as the collective unconscious, understood in the sense of Jung. It is shown that the neural network model of the noosphere makes it possible to formulate a similar concept of "professional collective unconscious", which is responsible for professional intuition, acts of creativity, etc. In turn, the existence of the professional collective unconscious forces us to radically reconsider the content of what is called training and move to the concept of meta-learning, which, among other things, involves stimulating transitions from one level of interaction with transpersonal information structures that make up the professional collective unconscious to another.
\end{abstract}

\section{INTRODUCTION}

There is no doubt that the forced transition to distance education in 2020 made the numerous systemic problems of modern higher education, at least post-Soviet, noticeably clear.

It is noted (Durães, D. et. al. 2021, Lichand, G. et. al. 2021) that remote training turned out to be much less effective than traditional classroom training. The level of assimilation of knowledge acquired by most students has fallen, although de facto, the real opportunities for their acquisition have not diminished. And before the pandemic, high qualifications of graduates were often the result of self-education.

This paper shows that the revealed difficulties should be viewed from the point of view of the contradictions inherent in modern higher education as an institution that emerged during the heyday of the Modern era, and far from fully meeting the realities of modern society.

Based on specific sociological material, it is proved that even with a relatively low motivation to assimilate new information, new knowledge (information) will be effectively assimilated by representatives of the corresponding age group, provided that the form of presentation of the material will correspond to the "logic of online networks", or rather, to the nature of modern infocommunication space, which by its nature is significantly different from the infocommunication space that existed a century ago.

As shown in this work, it is necessary to move to a different paradigm of higher education, and fundamentally new forms of education must correspond to it.

It is proved that the need for such a transition is dictated, first, by the qualitative transformations of the infocommunication space and the nature of its impact on each individual person.

\section{EXPERIMENTAL PART}

The experiments were carried out to determine the structure of preferences in the information space based on a survey of Crimean youth, which was carried out by the method of simple random sampling in December 2020. The sample size was 1200 respondents aged 18-35 years. The sample represents the youth of Crimea in terms of the main socio-demographic indicators. Sampling error $\approx 2.8 \%$.

We emphasize that conducting research in a particular region does not affect the generality of conclusions (due to the rapid spread, translation and assimilation of new semantic markers, value orientations and standards of social behavior that can neutralize the influence of established cultural models previously characteristic of specific regions). The determining factor in this respect is only the common language of the Internet environment.

There is no doubt that modern youth has transferred a significant part of their social activity to the Internet space. So, as the obtained data show, the Internet $(97.7 \%)$ uses the absolute priority in the information preferences of young people, which certainly corresponds to the general global trends: for comparison, $26.7 \%$ falls on television, and the print press $(8.3 \%)$ and radio $(7.6 \%)$ as sources of information are almost rudimentary in nature. At the same time, in the structure of preferences for obtaining information within the Internet space, social networks are a priority $(74.8 \%)$.

The structure of the information interests of young people reveals the nature of the motivation for their participation in information processes. News preferences by area of interest are distributed as follows.

Highest level: (cinema - 61.9\%, science and education - 53.6\%). 
High level: (culture - 48.3\%, incidents - 47\%, politics - 44.3\%). A third of respondents are interested in technology, fashion, sports, and celebrity news.

More than a quarter of the respondents are interested in the news of the economy (29.3\%) and the gaming industry (27\%).

Against the background of these spheres of interest, religious topics $(12.5 \%)$ have extreme positions.

Those who answered that they were not interested in news at all were only $4.9 \%$.

The results of answers to the question "For what purpose do you most often use the Internet correlate with the given data?" (Table 1). The entertainment sphere attracts the greatest attention of young people $(80.6 \%)$. It is noteworthy that the indicators of choosing the alternative "self-development" $(60 \%)$ are not much, but still outstrip the indicators of answers related to the search for information for study $(56.4 \%)$, i.e., the current situation in the field of education forces young people to focus more on self-development rather than on formal education.

Thus, in the youth environment, only partially overlapping spheres of social activity are formed, one of which satisfies the need for obtaining competencies, skills, and abilities, the second provides formal requirements for obtaining a diploma.

\begin{tabular}{|l|l|}
\hline $\begin{array}{l}\text { I watch TV shows and films, videos, listen to music } \\
\text { for entertainment }\end{array}$ & 80,6 \\
\hline for self-development, self-education, and training & 60 \\
\hline $\begin{array}{l}\text { for dating and communication, I use instant } \\
\text { messengers (Skype, Viber, Discord, WA, etc.) }\end{array}$ & 59,5 \\
\hline looking at photos, illustrations, memes & 56,7 \\
\hline looking for the information I need to study & 56,4 \\
\hline $\begin{array}{l}\text { looking for the right information for my hobbies and } \\
\text { hobbies }\end{array}$ & 51,1 \\
\hline watch / read news, blogs, forums & 47,3 \\
\hline $\begin{array}{l}\text { I use services (Internet banking, Government } \\
\text { services, My documents) }\end{array}$ & 44,2 \\
\hline to download and use useful programs & 43,3 \\
\hline download / read books, reviews for books & 37,5 \\
\hline using maps, searching for geolocations & 37,1 \\
\hline shopping & 36,1 \\
\hline playing, watching game streams, reviews & 34,2 \\
\hline $\begin{array}{l}\text { looking for vacancies, the necessary information for } \\
\text { work }\end{array}$ & 22,7 \\
\hline I read Astro forecasts, horoscopes & 15 \\
\hline to make money on the Internet & 14,2 \\
\hline
\end{tabular}

Table 1. Internet usage preferences, $\%$

The priority of the choice of entertainment content is also demonstrated by the data related to video views on the Internet. When answering the question "What topic do you regularly (at least once a week) watch videos on the Internet?" (Table 2) dominates the viewing of films, TV series and film reviews $(65.4 \%)$, humorous shows $(51.4 \%)$, music videos $(45.5 \%)$. It is noteworthy that watching videos for self-development and selfstudy $(27 \%)$ and scientific topics was included in the next block of answers (from 22 to $29 \%$ ) along with watching, for example, game streams $(29.7 \%)$, videos on the topic of fashion ( $23.2 \%)$ or famous persons and celebrities (22.2\%).

Scientific and educational information is far from the first positions. This indicates, among other things, the systemic shortcomings of scientific and educational content, its inconsistency with the requirements of a modern digital society.
With an overabundance of scientific and educational materials suitable for training professional personnel, there are few resources that would combine a) information content, b) concentrated presentation of material in an interesting format, and c) usefulness.

This fact speaks about the divergence of traditional and new, "digital" forms of education, about the futility of attempts to integrate outdated methods into the digital field.

\begin{tabular}{|l|l|}
\hline Movies, films, TV series, movie reviews, cartoons & 65,4 \\
\hline Humor & 51,4 \\
\hline Music, video clips & 45,5 \\
\hline Game streams, game reviews & 29,7 \\
\hline Culture, art, virtual tours & 27,8 \\
\hline $\begin{array}{l}\text { Master classes, self-study, self-development } \\
\text { trainings, learning other languages }\end{array}$ & 27 \\
\hline Food preparation, recipes, tastings & 25,2 \\
\hline Fashion, cosmetics & 23,2 \\
\hline Travel, nature, animals & 22,9 \\
\hline Science, technology, discoveries & 22,7 \\
\hline About famous people, celebrities & 22,2 \\
\hline Politics, society & 22 \\
\hline Automotive & 17 \\
\hline $\begin{array}{l}\text { Psychology, personal development trainings, } \\
\text { motivational videos }\end{array}$ & 16,9 \\
\hline Economics, business, startups, business trainings & 13,9 \\
\hline Reviews of electronics, gadgets & 12,4 \\
\hline Incidents and crime & 12,3 \\
\hline Sports programs & 12,3 \\
\hline $\begin{array}{l}\text { Reviews and testimonials on products that have } \\
\text { been looked after for purchase }\end{array}$ & 11,8 \\
\hline Homemade products (do it yourself) & 10,1 \\
\hline Sports training programs & 9,2 \\
\hline Using programs and applications & 8,7 \\
\hline Programming & 6,9 \\
\hline Religion & 4,5 \\
\hline Hard to answer & 1,2 \\
\hline None of the above interests & 1 \\
\hline
\end{tabular}

Table 2. Interests in regular (at least 1 time per week) viewing of video content on the Internet, \%

Scientific and educational information is far from the first positions. This indicates, among other things, the systemic shortcomings of scientific and educational content, its inconsistency with the requirements of a modern digital society. With an overabundance of scientific and educational materials suitable for training professional personnel, there are few resources that would combine a) information content, b) concentrated presentation of material in an interesting format, and c) usefulness.

This fact speaks about the divergence of traditional and new, "digital" forms of education, about the futility of attempts to integrate outdated methods into the digital field.

The general logic of disseminating information and attracting the attention of consumers (especially young people) is obvious. 
Vivid content of entertainment content, offering to enjoy the perception of information, brings you on the path of least resistance, where the application of the least effort is required. On the contrary, the assimilation of scientific and educational content requires significant efforts, especially at the level of comprehension and assimilation of information. In addition, the rapid turnover of information (especially on social networks, on video hosting sites and in news feeds) creates an effect that we conditionally call the information loop. A consumer of information can "stick" in the information space for a long time without a specific goal. In our research, to the question "Over the past month, have you had cases when you could" stick "on the Internet for a long time, aimlessly wandering around sites, from page to page?" $70 \%$ of the respondents answered in the affirmative.

Thus, the following global trends are evident: a) an overabundance of information, b) its rapid updating, c) the priority of broadcasting and assimilation through social networks, d) the general orientation of the information field towards entertainment content.

Against this background, scientific and educational programs and related sources of information demonstrate poor adaptation to modern realities. This, of course, does not mean at all that science and education should completely switch to the "language" of short messages, sketches, memes, etc. As will be clear from what follows, a radical rethinking of what is called education is needed.

Another important aspect in understanding the nature of the modern information space and the structure of preferences within it is the personal factor. The main transmitters of information in the current conditions are not politicians or experts in various fields, but media figures.

It is they who become the leaders of public opinion, and the information they broadcast is much easier and more efficiently assimilated by consumers (and primarily by young people), transferred to their value attitudes and, ultimately, to their models of sustainable social behavior.

In the study of the attitudes of young people, the respondents were asked the question "Which of the listed media figures, in your opinion, is the leader of public opinion for today's youth in Russia?" Without listing all the figures, we would like to note that more than a third of the respondents could not give a clear answer to the question about the leaders of public opinion (I find it difficult to answer - $18.4 \%$; none of the above $-17.2 \%$ ). Of those who decided on the answer, they named Y. Dud (37.6\%) and A. Navalny (29\%). Morgenstern (16.5\%) and A. Ivleeva $(16.4 \%)$ shared the third place with a large margin. 4 th and 5th places went to blogger E. Bazhenov (BadKomedian) and athlete $\mathrm{H}$. Nurmagomedov $-15.3 \%$ and $12.1 \%$, respectively. Olga Buzova and Oksimiron received 8.8 and $8.4 \%$.

It is important to emphasize that the point is not in the specific media figures mentioned, but in the fact that most of them belong to the show-format-oriented media segment. Thus, it is they, and not experts, scientists, or teachers, who set the sociovalue orientations of today's youth.

Among the shortcomings of the educational system under consideration, respondents indicated a decrease in their own motivation, fatigue, deconcentration of attention and deterioration in health due to the forced long-term work at the computer, as well as a lack of communication with fellow students and teachers. A third of the respondents noted such shortcomings as technical failures and a decrease in the quality of teaching. $22 \%$ of respondents noted that they feel psychological discomfort and depression. When assessing the prospects for distance education in the future, only a small part of the respondents noted the advantages of distance learning for students and agreed with the possibility that distance learning could replace traditional education (13.8\%). The majority see it as either additional forms used in conjunction with traditional education $(47 \%)$, or as a temporary measure in emergency situations $(24.7 \%) .8 .8 \%$ noted that the distance has only disadvantages and creates a lot of inconveniences for students.

Thus, in the context of the digitalization of social relations in general and education in particular, the increasing immersion of people in a new information environment, which for young people becomes almost a natural habitat, new conditions for the functioning of almost all public institutions are being formed and the sphere of higher education cannot be an exception.

\section{RESULTS AND DISCUSSION}

\subsection{The higher education system as part of the global communication environment}

One of the conclusions that can be drawn from the presented experimental material lies on the surface: information sources compete for the attention of users / consumers / recipients, and not vice versa. Useful information turns out to be supplanted by anything, for example, those theses voiced by the leaders of public opinion, which were discussed in the previous section. This, however, is only the most obvious manifestation of the transformations that the global communication environment has undergone.

We emphasize that the effectiveness of the student's assimilation of the material de facto is often considered without consistently considering the impact of his communication environment. Of course, there are works in the literature that analyze the peer education factor (Karaca, Aysel et. al. 2017, Gurjanov, A et. al. 2020). However, considering this factor (as well as those like it) does not allow us to fully trace how exactly the transformations of the global infocommunication environment affect students and their reactions to informational influences that form the basis of higher education.

Let us formulate the following thesis: any informational influences are assimilated by an individual as efficiently as possible when they are assimilated by the infocommunication environment, and those informational influences that together make up the educational process are no exception.

In other words, a student's knowledge is far from only the result of his personal efforts and the skill of teachers. This is a kind of projection of information assimilated by the infocommunication space onto the personal consciousness of an individual. Let us show that this thesis is by no means a metaphor - there is a welldefined objective reality behind it. Let us show it.

At the beginning of the twentieth century, several prominent thinkers Edouard Leroy, put forward concepts associated with the term "noosphere" (Le Roy 1956). In the Russian-speaking scientific tradition, this term is firmly associated with the name of V.I. Vernadsky, who considered the noosphere as the next (predicted) stage in the evolution of the biosphere (Bailes, K. E. 1986).

The ideas of V.I. Vernadsky are currently being actualized since the concept of the noosphere is related to the issue of the essence of intelligence, which has recently acquired relevance in connection with the problems of artificial intelligence (Suleimenov, I.E. et. al. 2019, Suleimenov, I.E. et. al. 2020, Vitulyova, Y.S., 2020).

It is generally accepted that human consciousness is purely individual. However, consider two people entering a dialogue. At first glance, two people are communicating here, but in reality, we are talking about the exchange of information between neurons localized within the brain of each of the interlocutors (Fig. 1). 


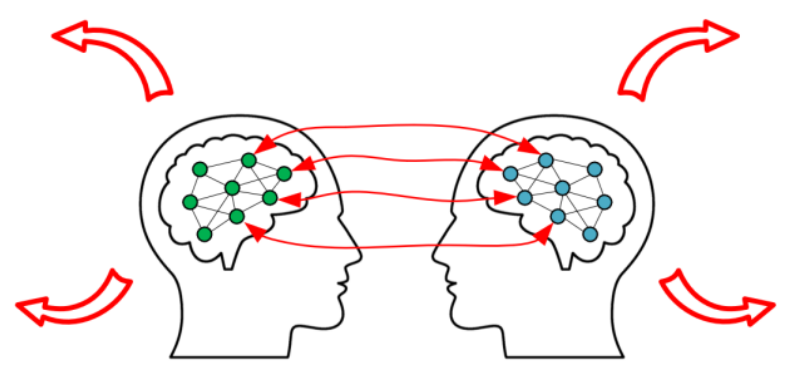

Figure 1. Illustration for the formation of a global neural network - noosphere

Continuing this logic, it is easy to conclude about the existence of a global neural network, which, with some reservations, can be identified with the noosphere, understood in the spirit of V.I. Vernadsky.

Further, as is proved in modern neuroscience, the informational capabilities of a neural network nonlinearly depend on the number of neurons included in it. Consequently, if a global neural network is formed because of interpersonal communications, then this global network must have some additional qualities that cannot be reduced to the properties of individual fragments of the neural network localized within the brain of everyone.

We emphasize that this thesis has already been formulated in the humanitarian literature. There is such a concept as public consciousness, and in the philosophical literature it is proved that public consciousness is not reduced to the consciousness of individuals. This is something qualitatively different. In the same row are such concepts as mentality, socio-cultural code, and so on.

In other words, the basic methodological premises of the modern theory of neural networks make it possible to interpret those phenomena that have long been reflected in the humanities literature. It is also necessary to consider that for the functioning of a neural network as a whole, it is absolutely unimportant through which channels the exchange between the neurons that make up the network takes place. A neural network can be, somewhat exaggerated, assembled on any element base. For example, a fairly simple design of an optical neural network can be proposed. Moreover, many physicochemical systems can also be considered based on analogies with neural networks, and this approach allows us to shed light on the mechanisms of evolution that precedes biological (Kalimoldayev, M.N. et. al. 2019, Chen, M. et. al. 2019, Mun, G.A. et. al. 2020). In other words, the localization of individual fragments of the neural network within the brain does not in any way affect the conclusion about the existence of the global network as a whole. Consequently, it must be admitted that human consciousness and human intellect are only relatively separate. There are also transpersonal information structures that are formed due to the exchange of signals between neurons in the same way as due to such exchange - but only occurring within a separate fragment of the global neural network, localized within the brain - the intelligence and consciousness of an individual person are formed.

The most visible of this kind of transpersonal information structures is natural language. The following thesis of Umberto Eco is well known: "It is not we who speak with our language, it is our language that speaks by us." The language is de facto fixed not in local segments of the global communication network, it is fixed in the network as a whole.

It is obvious that there can be quite a lot of such transpersonal information entities, and the intellect and consciousness of a person cannot but be associated with them. There is every reason to believe that a significant part of what is called consciousness and intelligence is a kind of projection of entities developing in the transpersonal information space onto a relatively independent fragment of the noosphere - the human brain.

Paradoxically, this conclusion forces a radical change in the views of what is called education. Let us show that education is de facto a sequence of qualitative transitions from one state to another, which can and should be viewed through the prism of the individual's interaction with the global communication environment.

\subsection{Meta-education thesis: basic premises}

There is such a thing as functional illiteracy. A person who has studied in elementary school can understand the meaning of the letters of the alphabet, will be able to form words from them, but this will require considerable effort from him. Otherwise, there is a qualitative leap, because of which the ability to read and enjoy reading - becomes an integral part of this personality. The situation is similar with the subsequent stages in education, in any case, this certainly applies to technical or natural science specialties.

The ability to use the integral or calculus of variations is also easily classified according to functional "literacy" - functional "illiteracy". In one case, an individual automatically uses the basic provisions of the calculus of variations, for example, to understand the principles of "maximum and minimum" used by various disciplines, in the other - he can, referring to reference books and other manuals, recreate the line of reasoning of the author of the read text, but this will require him more than serious work.

It can be argued that mastering the apparatus of the integral or calculus of variations is impossible without its "incorporation" into the structure of the personality. In any case, a person who has mastered this mathematical apparatus at a truly professional level will use it almost unconsciously, just as he will not think about the sequence of movements of the right and left legs during normal walking. More precisely, a person who has really mastered a certain system of concepts begins to think differently, in other categories. De facto, there is a change in his intellect, which, in accordance with the results of the work (Suleimenov, I.E. et. al. 2019, Suleimenov, I.E. et. al. 2020, Vitulyova, Y.S., 2020), should be considered, first, as a system of information processing.

The differences between formal knowledge of the calculus of variations and the situation when such knowledge caused qualitative changes in intelligence can be traced even at the level of the nature of the reader's interaction with the corresponding texts. In one case, his reaction when reading a text in which a reference to "extreme principles" appears, will be natural for a person of the corresponding level of literacy; in the second, he will have to work hard to understand the content at least at the primary level.

A similar conclusion can be drawn in relation to almost any technical or natural science discipline. It is customary to say that a chemistry student "sees" (or does not see) the structure of redox reactions, an electronics student "sees" the distribution of currents in a transistor circuit, and so on.

Thus, any education is a certain sequence of transitions from quantity to quality.

Solving problems, assimilating specific material and everything else that university programs provide, serves as nothing more than a "raw material", a collection of primary information, which - according to a hitherto unknown mechanism sometimes provides a transition to the next level of "literacy". The student either really knows how to integrate or not. In any 
case, if integration is hard work for him, he will do everything so as not to resort to it and, therefore, exclude its use in his subsequent professional activities.

The next - in relation to "just professional" - the level of competence also requires a quite definite (and much deeper) structural restructuring of consciousness and intellect. It is at this level that persons for whom inventive and other innovative activities are their daily professional work operate.

All these considerations can be interpreted from the point of view of the formation of transpersonal information structures in the global infocommunication space (noosphere), which were mentioned above.

Indeed, any scientific theory is obviously an information object formed at the transpersonal level of information processing. In this sense, it is like a natural language that "speaks by us", in accordance with the aphorism of Umberto Eco used above with the obvious amendment that in this case we are talking about a relatively small scientific community.

Consequently, those qualitative transitions, which were mentioned above, and which constitute the true content of what is called "education", can be considered from the point of view of "connecting" an individual to ever higher information structures developing at the transpersonal level of information processing - in the noosphere. Its creation becomes open to these structures, and it is important to emphasize that we are not talking about simply assimilating certain information. The human intellect, being reconstructed, turns out to be able to perceive - according to poorly studied mechanisms - huge amounts of information in the most compact form. In ordinary language, this is interpreted as professional intuition, the ability to quickly make decisions, find the right path with a minimum amount of initial data, etc. We emphasize that such abilities, which leave the true essence of professionalism, are rather weakly correlated with the total volume of accumulated information. So much so that at the present stage of research it is quite permissible to speak of some kind of "professional unconscious" (the term is formed by analogy with the "collective unconscious", understood in the spirit of Jung (Jung C. G. 2017)), the possession of which makes a person a true professional in his field.

The existence of the professional unconscious is especially vividly manifested at the level of the ability to generate innovations (more broadly, to engage in creativity) in the course of everyday work. The mechanisms of creativity remain, to put it mildly, poorly understood, but the fact that factors not associated with linear thinking (intuition, the ability to think outside the box, etc.) play a huge role in them.

Let us emphasize that from the point of view of the above neural network concept of the noosphere, the collective unconscious receives a consistent natural-scientific interpretation. As soon as the creation of a person is formed only by a local fragment of the noosphere and, therefore, is only partially independent, then certain "direct" mechanisms of his interaction with the global infocommunication environment cannot but exist. The manifestations of such mechanisms do not have to be fully realized. Simplifying, under certain conditions, the brain of a particular person can directly "connect" to the noosphere, which provides the ability to process information as efficiently as possible.

Based on the foregoing, it is permissible to formulate a thesis about meta-education, which provides for the need to create techniques that allow the most efficient (in terms of time and effort) way to move from one level of interaction with the global infocommunication environment to another. Let us emphasize once again that the highest form of professionalism the ability to create in the mode of routine professional activity is obviously associated with the "professional collective unconscious", which is formed according to the same mechanisms as the collective unconscious, understood according to Jung.

The upbringing of a professional of this level in higher education de facto remains a matter of chance, which is not surprising - the corresponding mechanisms remain poorly understood. However, one of the main goals of university education is to educate professionals of this level - after all, it was they who provided and ensured what is called progress.

Consequently, it remains only to admit that in solving one of the key tasks, higher education acts haphazardly. The assertion that universities "provide knowledge" reflects, first, the level of our lack of understanding of how a truly professional way of thinking is formed. For many centuries, higher education has been de facto "firing across the squares", communicating a huge amount of various information to many students, in the not unfounded hope that one of the huge number of shells fired simply according to the laws of statistics - will hit the target.

Until a few decades ago, this approach was acceptable. In any case, it remained effective enough for the inertia of social systems to compel the preservation of higher education in the form in which it took shape at the beginning of the Second Industrial Revolution. Currently, this approach not only loses its effectiveness - but it also stops working altogether, for which there are objective reasons discussed below.

\subsection{Meta-education as a way out of the crisis of modern higher education}

At the beginning of the twentieth century, two tendencies developed in world science, which by the beginning of the current century led to a large-scale crisis in higher education that affected the whole world. This is the professionalization of science and the formation of its disciplinary structure.

Undoubtedly, these tendencies have developed for objective reasons. Science provided society with more and more significant results, which predetermined a significant increase in the number of professional scientific workers. The increase in the volume of scientific results, accompanied by a rapid increase in the number of scientific publications, could not but lead to an ever more detailed differentiation of knowledge.

The negative consequences of such differentiation have fully manifested themselves at the present time. Even though the thesis about the need for interdisciplinary cooperation was proclaimed a long time ago and today has earned universal recognition, in practice such cooperation remains insufficiently effective. De facto there are no tools that could provide systemic interdisciplinary interaction. This leads to the fact that most scientific workers irreversibly lose the idea of a holistic picture of the world - only an extremely separate fragment remains in the field of view, and it is so narrowed that it becomes more and more difficult to create something new.

We emphasize that in accordance with the general concepts of history and philosophy of science, any scientific discipline especially a narrow one - is de facto a reflection of the existence of a well-defined research program (the term is understood according to Imre Lakatos (Lakatos Imre 1970)). In turn, any such program has an ultimate development potential, which will sooner or later be exhausted.

Provided that the entire edifice of science is divided into separate programs that have taken the form of independent disciplines (and administratively codified), and there are no tools for creating new programs (at least at the system level), the potential for the development of science as a whole is exhausted. At present, this thesis is no longer surprising. Thus, the Club of Rome in its anniversary report (Weizsacker E.U., Wijkman A. 2018) put forward the thesis of the need for the 
formation of the New Enlightenment. This thesis reflects an obvious fact - there is an urgent need to move from a fragmented picture of the world to a holistic one. Obviously, it is impossible to create such a picture by means of specific sciences, especially those that have disintegrated into many independent scientific areas.

Moreover, the need to return to a holistic worldview, which was given by university education at the turn of the 19th and 20th centuries, is dictated by obvious pragmatic considerations, which, however, turn out to be closely related to the existence of the professional collective unconscious.

The increasingly complex disciplinary structure of science led to the fact that throughout the twentieth century, the graduating departments of universities also became more and more highly specialized, and this trend continues to this day. This carries significant risks.

The barriers associated with the development of an increasingly detailed disciplinary structure of science could not but lead to the gradual destruction of the professional environment. Metaphorically speaking, the first victim of the formation of the disciplinary structure of science was the professional collective unconscious, that is, the totality of not fully understood factors that makes a professional a professional.

The most striking evidence of this process is more than a sharp decline in the prestige of philosophy in the eyes of most scientists in the twentieth century. Of course, this was promoted in every possible way by the tendencies developing in the philosophy of the twentieth century, but in relation to the problem under consideration, the attitude to philosophy as an unproductive thinking suggests, first, that the integral scientific picture of the world in the eyes of most graduates of post-Soviet universities has finally lost its value. For orientation in the world around them, they are content with judgments available to any layman.

From the point of view of the neural network theory of the noosphere, this is one of the main markers of the destruction of the professional collective unconscious. Judgments (or even vague sensations) that allow one to go beyond the ordinary, and precisely at a professional level, cannot be generated otherwise than based on a more or less holistic picture of the surrounding world. A person professionally engaged in innovations should be able to see the world "philosophically" - either through reflection given by the appropriate level of knowledge, or to one degree or another unconsciously, due to what was called above "professional collective unconscious". The latter, among other things, provides a kind of substitute for philosophical reflection, just as a person integrated into a specific social environment is capable of unconsciously adequate actions.

Modern higher education is faced with a very definite contradiction.

On the one hand, a huge amount of scientific and technical information is an objective reality, the need to operate with which has led to the emergence of a ramified disciplinary structure of science. On the other hand, the existence of such a ramified disciplinary structure of science is one of the main factors that determine the crisis phenomena in modern higher education.

This contradiction, if you remain in its own plane, is insoluble, therefore, in full accordance with dialectics, the way out must be sought by going beyond this plane.

Hence - the thesis about meta-education as the basic one for the new paradigm of higher education, overcoming the above contradiction.

Somewhat exaggerating, it can be expressed as follows. The resources of that component of human intelligence, which is purely individual, are limited. Modern higher education has de facto approached the limit of the possibilities of their use, the student is either drowning in the flow of information or refuses to perceive most of it. Consequently, there is nothing left to do but to use other resources - resources determined by the existence of a collective professional collective unconscious and ensuring a directed transition to a different level of interaction with transpersonal information structures.

\subsection{Applied Philosophy and Business Education Ecosystems: Tools for the Transition to Meta-Education}

The proposed concept is basically amazingly simple. The most important link between the noosphere and the personal level of information processing are meanings (understood in the philosophical meaning of this term), and their guides to the information space are people who, according to L.N. Gumilyov should be attributed to passionaries (to simplify, these are people driven by a certain passion, certain aspirations, often having nothing to do with mercantile interests). History, including the history of science, knows many examples of outstanding figures who went forward, despite any hardships.

Modern pedagogy recognizes that the effectiveness of the educational process most significantly depends on the emotional state of students (Kowalska, Joanna et. al. 2021). However, this thesis does not need proof: for example, if the teacher is boring, they will not listen to him.

This thesis is related to the issue of passionarity: only it can give the appropriate emotional intensity when it comes to studies or creativity. Simplifying, only a large-scale idea that leads an intellectual can make him devote many years to solving a particular problem (or a long and difficult study), especially if we consider that material reward in such cases is always questionable.

Outstanding discoveries have always been made by people keen on this or that idea. This fact is recognized by all historians of science, but the time has come to extend it to students. Studying - especially in modern conditions - is extremely hard work, and often thankless. The Internet is replete with messages about how uneducated and narrow-minded people achieved success - and the accompanying material benefits; the corresponding views are latently promoted into the youth consciousness and modern mass culture. A young man, who prioritizes the acquisition of knowledge, is de facto forced to oppose himself to the modern youth environment. To dare to do this, you need to have more than significant motivation. It can only be given by adherence to a certain idea, or rather, it arises when the student assimilates this or that meaning (in the philosophical meaning of this term). To our great regret, modern higher education has ceased to transmit meanings to society, at least those that are capable of leading passionaries. In some cases, higher education de facto appeals to the meanings of past eras (for example, when students are taught thermodynamics, setting out only the formal mathematical side of the matter, forgetting about its ideological component), and in others, it broadcasts meanings that are aimed specifically at most students, maximally easily digestible and uninteresting for those who would potentially be ready for much more - uninteresting for passionaries.

It is this circumstance that is demonstrated by the results of sociological measurements presented above. The main problem of modern higher education is the lack of ideas capable of leading gifted and thinking people along with them. In theory, the responsibility for generating ideas of this level rests with philosophy, in any case it was philosophy that performed this function almost until the middle of the twentieth century.

Modern philosophy - in its understanding, which is shared by most philosophy teachers in post-Soviet universities - is 
hopelessly far from thinking about this problem and even only recognizing its existence.

Hence - the thesis about the fundamental importance of applied philosophy for ensuring the modernization of higher education, for its transition to a different level. The international expert community de facto recognizes the need for such modernization, but the main thing is missing from the field of vision - the university cannot be oriented towards the majority, otherwise it ceases to be a University, which we are now observing, at least in the post-Soviet countries.

The problem is that the University is currently being managed according to the same organizational / administrative schemes as any industrial corporation. Simplifying the "production of specialists" are trying to put on the same conveyor as the production of cars. The result could be predicted in advance - a specialist trained within the framework of some strict regulations will be so only in name, at least in terms of his ability to generate new ideas.

Let us formulate the basic thesis of the concept of metaeducation. The university is, first, an environment that provides the generation of meanings and is intellectually comfortable for those who are able to move forward. It is due to this that it turns out to be able to perform the functions of a connecting link between higher information structures and that segment of the infocommunication space that is accessible to the perception of the layman.

Accordingly, the main task of the University is to set a super task for those who deserve it. Not to teach, it is secondary, but to lead.

This thesis is also not new, it is about this that the most talented teachers have been talking about from the centuries. The question is how to implement this in practice in modern conditions.

Paradoxically, in modern conditions this returns to the cultural function of universities, which they knowingly performed during their heyday.

Ideas worthy of this name are generated by the cultural environment - and this is proved by the entire history of the development of science.

Accordingly, the meta-education thesis is revealed through the creation of an appropriate cultural environment in universities. Business educational ecosystems are becoming a practical tool here, focused, among other things, on performing the functions that bloggers perform - on arousing interest in something more than non-standard, falling outside the boundaries of the ordinary.

Simplifying as much as possible, the "rebellious spirit" of young people can and should be used for good. In modern conditions, the point of application of efforts of this kind certainly exists, this is an outdated approach to comprehending the world, focused on the ramified disciplinary structure of science. Scientific bureaucracy has long become its personification for any thinking student, and its very existence can become more than a significant mobilizing factor, as shown by the experimental data presented above.

Of course, real schemes of business educational ecosystems require further elaboration, but this issue is already beyond the scope of this article.

\section{CONCLUSION}

Thus, the neural network model of the noosphere, which proves the existence of transpersonal information objects, makes it possible to radically reconsider the point of view on the essence of what is called education

Traditional pedagogy does not take into account the existence of a professional collective unconscious responsible for professional intuition, acts of creativity and other manifestations of genuine professionalism that cannot be taught by traditional methods. At the present stage, when the transformations of the nature of the global communication environment have a pronounced negative impact on the higher education system as a whole, it is advisable to switch to meta-education. It implies stimulating a directed transition from one level of interaction with transpersonal information objects that form the professional collective unconscious to another. The main tool here is the cultural environment, which is formed by the University, which makes it possible to use the potential of the professional collective unconscious to dramatically increase the effectiveness of education.

\section{REFERENCES}

Bailes, K. E.,1986: Soviet science in the Stalin period: the case of VI Vernadskii and his scientific school, 1928-1945. Slavic Review, 45(1), 20-37. https://doi.org/10.2307/2497919

Chen, M., Challita, U., Saad, W., Yin, C., Debbah, M., 2019: Artificial neural networks-based machine learning for wireless networks: A tutorial. IEEE Communications Surveys \& Tutorials, $\quad$ 21(4), 3039-3071. DOI: 10.1109/COMST.2019.2926625

Durães, D., Toala, R., Novais, P., 2021: Emotion Analysis in Distance Learning. Educating Engineers for Future Industrial Revolutions, 1328, 629. 10.1007/978-3-030-68198-2_58.

Gurjanov, A, Zakoldaev, D, Shukalov, A, Zharinov, I., 2020: Peer to peer Education 4.0. Journal of Physics: Conference Series. 1691. 012153. 10.1088/1742-6596/1691/1/012153.

Jung. C. G., 2017: Die archetypen und das kollektive unbewussten C. 496 ISBN-13: 978-3843601276

Kalimoldayev, M.N., Suleimenov, E.I., Pak, I.T., ...Yevstifeyev, V.N., Mun, G.A., 2019: To the question of physical implementation of optical neural networks. News of the National Academy of Sciences of the Republic of Kazakhstan

Karaca, Aysel akkuş, Dilek Sener, Dilek., 2017: Peer Education from the Perspective of Peer Educators. Journal of Child \& Adolescent Substance Abuse. $27 . \quad 1-10$. 10.1080/1067828X.2017.1411303.

Kowalska Joanna, Wójtowicz Dorota, Szczepańska-Gieracha, Joanna, 2021: Physical Activity and the Emotional State of Physiotherapy Students Who Finish Their Education. International Journal of Environmental Research and Public Health. 18. 4572. 10.3390/ijerph18094572.

Lakatos Imre, 1970: Methodology of Scientific Research Programme

Le Roy, Edouard Essai d'une philosophie première, 2 vol., 1956-1958.

Lichand, G., Dória, C. A., Neto, O. L., Cossi, J., 2021: The Impacts of Remote Learning in Secondary Education: Evidence from Brazil during the Pandemic. 10.21203/rs.3.rs-568605/v1.

Mun, G. A., Moldakhan, I., Serikbay, A. M., Kaldybekov, D., Suleimenov, I. E., Park, K., 2020: Hydrophilic interpolymer associates-the key to solving the problem of pre-biological evolution. International Journal of Biology and 
Suleimenov, I.E., Gabrielyan, O.A., Bakirov, A.S., Vitulyova, Y.S., 2019: Dialectical Understanding of Information in the Context of the Artificial Intelligence Problems. IOP Conference Series: Materials Science and Engineering. 630(1), 012007. 10.1088/1757-899X/630/1/012007/

Suleimenov, I.E., Vitulyova, Y.S., Bakirov, A.S., Gabrielyan, O.A., 2020: Artificial Intelligence: What is it? ACM International Conference Proceeding Series. 22-25. https://doi.org/10.1145/3397125.3397141

Vitulyova, Y.S., Bakirov, A.S., Baipakbayeva, S.T., Suleimenov, I.E., 2020: Interpretation of the category of complex in terms of dialectical positivism. IOP Conference Series: Materials Science and Engineering. 946(1), 012004. 10.1088/1757-899X/946/1/012004

Weizsacker E.U., Wijkman A. Come On! Capitalism, Shorttermism, Population and the Destruction of the Planet - A Report to the Club of Rome //URL: https://batrachos.com/sites/default/files/pictures/Books/Weizsac ker_Wijkman_2018_Come\%20on.pdf 